\title{
Comunidade epifítica vascular do Parque Estadual da Serra Furada, sul de Santa Catarina, Brasil
}

\author{
Peterson Teodoro Padilha*1, Ronaldo dos Santos Junior ${ }^{2}$, San Zatta Custódio ${ }^{3}$, \\ Lislaine Cardoso de Oliveira ${ }^{4}$, Robson dos Santos ${ }^{5}$ e Vanilde Citadini-Zanette ${ }^{6}$ \\ 1,3,4,5,6 Programa de Pós-Graduação em Ciências Ambientais (PPGCA),Universidade do Extremo Sul Catarinense - \\ UNESC, SC- Brasil \\ ${ }^{2}$ Programa de Pós-Graduação em BotânicaUniversidade Federal do Rio Grande do Sul - UFRGS- Brasil
}

\begin{abstract}
Resumo
O bioma Mata Atlântica é um conjunto complexo de ecossistemas tropicais, com grande importância, por abrigar uma parte representativa da biodiversidade brasileira e mundial. Os epífitos vasculares, uma categoria quase exclusiva das florestas tropicais, representam aproximadamente $10 \%$ de todas as plantas vasculares, podendo atingir mais de $25 \%$ das espécies em países com este tipo de formação. O objetivo deste estudo foi o de realizar levantamento florístico, estrutural e distribuição espacial vertical da comunidade epifítica vascular presente no Parque Estadual da Serra Furada (PESF), uma unidade de conservação do bioma Mata Atlântica, localizada no sul do Estado de Santa Catarina, sul do Brasil. As espécies foram amostradas em seis transectos estabelecidos ao longo da floresta no PESF. Em cada transecto foram demarcados cinco pontos quadrantes centrados, sendo consideradas as árvores mais próximas com DAP $10 \mathrm{~cm}$ como uma unidade amostral. Cada árvore foi dividida em duas zonas verticais, fuste e copa, onde a presença de epífitos foi registrada. Amostragem adicional foi realizada pelo método de caminhamento pela floresta, a fim de fornecer uma lista florística mais completa. Foram estimados, como parâmetros estruturais, as frequências absoluta e relativa em árvores, troncos e copas, e o valor de importância. Como resultado, 115 espécies de epífitos vasculares foram registrados. Orchidaceae foi a família mais rica, com 38 espécies, seguida de Bromeliaceae e Polypodiaceae, com 23 e 14 espécies, respectivamente. As categorias ecológicas incluíram 94 espécies (81,7\%) de holoepifitos verdadeiros, enquanto que as estratégias de polinização e dispersão mais frequentes foram entomofilia $(66,7 \%)$ e anemocoria $(56,5 \%)$, respectivamente. A frequência e a riqueza de espécies mostraram diferenças significativas entre fustes e copas, com valores mais elevados na copa, apontando como ambiente favorável. Os coeficientes de correlação revelaram aumento significativo da riqueza de espécies de acordo com a altura e DAP de forófitos. Os resultados apontam que quanto maior a altura e diâmetro das árvores, maior será a diversidade de espécies epifíticas, evidenciando a importância de preservar as florestas.

Palavras-chave: Método ponto-quadrante. Diversidade. Forófito. Dossel. Floresta Ombrófila Densa Montana.
\end{abstract}

\begin{abstract}
The Atlantic Forest biome is a complex assemblage of tropical ecosystems with a unique importance for harboring a representative part of the Brazilian and global biodiversity. Vascular epiphytes, an almost exclusive category of tropical forests, represent approximately 10\% of all vascular plants and may achieve more than $25 \%$ of the species in countries with this type of formation. The purpose of this study was to carry out a floristic and structural survey of vascular epiphytes, including vertical spatial distribution, in the Serra Furada State Park (SFSP), a conservation unit of the Atlantic Forest biome, located in the South of Santa Catarina State, Southern Brazil. Epiphytic species were sampled along seven transects established along an elevation gradient in the SFSP. Each transect comprised five point-centered quadrants, were the nearest tree with a $D B H \geq 10 \mathrm{~cm}$ was considered as a sample unit. Each tree was further divided into two vertical zones, bole and crown, where the presence of epiphytes was registered. Additional sampling was performed by a "walking method" across the forest, in order to provide a more complete floristic list. Absolute and relative frequency on trees, boles and crowns were estimated as structural parameters, and an importance value was then calculated to provide a general species ordination. As a result, 115 species of vascular epiphytes were registered. Orchidaceae was the richest family, with 38 species, followed by Bromeliaceae and Polypodiaceae, with 23 and 14 species, respectively. Ecological categories included 94 species (81.7\%) of true epiphytes, while the most frequent pollination and dispersion strategies were entomophilous $(66,6 \%)$ and anemochorous (56,5\%), respectively. Species frequency and richness showed significant differences between boles and crowns, reflecting higher values in the most favorable crown environment. Correlation coefficients showed a significant increase of species richness according to height and DBH of phorophytes. The results point out that the greater the height and diameter of trees, the greater the diversity of epiphytic species, highlighting the importance of preserving the forests.
\end{abstract}

Keywords: Point-quadrat method. Biodiversity. Phorophyte. Canopy. Montana Dense Ombrophilous Forest. 


\section{Introdução}

A proximadamente $9 \%$ de todas as plantas vasculares são epífitas (ZOTZ, 2013), sendo encontradas quase exclusivamente em florestas tropicais, chegando a representar mais de $25 \%$ das espécies em muitos países (KERSTEN, 2006). No Brasil, a Mata Atlântica apresenta, aproximadamente, 225 gêneros de 35 famílias de plantas vasculares com esta forma de vida (WAECHTER, 2008).

O epifitismo viabiliza o enriquecimento da diversidade nas florestas, propiciando a ocupação dos diferentes estratos, criando ambientes passiveis a manutenção da vida não dependente exclusiva ou diretamente do solo (BENZING, 1990; MADISON, 1977; WAECHTER, 1992), tornando-se responsável por parte significativa da diversidade que faz das florestas tropicais úmidas um dos mais complexos ecossistemas da biosfera (KERSTEN; SILVA, 2001).

A importância ecológica dos epífitos vasculares está ligada à manutenção da diversidade biológica e no equilíbrio interativo entre as espécies. Este grupo de plantas proporciona recursos alimentares como frutos, néctar, pólen e água, além de microambientes especializados para a fauna constituída por uma infinidade de organismos voadores, arborícolas e escansoriais (WAECHTER, 1992). A massa vegetal epifítica também exerce influência sobre a ciclagem de água e nutrientes no interior da floresta (INGRAM; NADKARNI, 1993). Essas plantas são comumente divididas em dois grandes grupos: holoepífitos, encontrados sempre ou quase sempre na condição epifítica; e hemiepífitos, que apresentam contato com o solo em pelo menos uma fase do seu ciclo de vida (BENZING, 1990). Este autor subdivide os dois grupos em cinco classes: holoepífitos característicos (ou obrigatórios), holoepífitos facultativos, holoepífitos acidentais, hemiepífitos primários e secundários.

O padrão de distribuição espacial para as espécies epifíticas pode variar basicamente nos sentidos horizontal e vertical, dado pelas diferentes regiões geográficas onde ocorrem, tipos de florestas e forófitos (distribuição horizontal) e pela variação na ocorrência da base até o topo da árvore (distribuição vertical) (REITZ, 1983; STEEGE; CORNELISSEN, 1989).

No Brasil o epifitismo vascular tem sido pouco abordado (KERSTEN; SILVA, 2001; CAGLIONI et al., 2012). Os trabalhos estão, de maneira geral, concentrados nas planícies litorâneas ou nas serras que as seguem (KERSTEN et al., 2009). No sul do Brasil, no estado do Paraná, podem ser citadas as pesquisas de Cervi e Dombrowski (1985), Cervi et al. (1988), Britez et al. (1995), Dittrich et al. (1999), Kersten e Silva (2002), Borgo e Silva (2003); Kersten (2006) e Bianchi e Kersten (2014) em Floresta Ombrófila Mista, de Borgo et al. (2002) em Floresta Estacional Semidecidual e Kersten e Silva (2006) em uma floresta inundada. Podem ainda ser mencionados, no Rio Grande do Sul, os trabalhos de Aguiar et al. (1981),
Waechter (1992), Gonçalves e Waechter (2002), Rogalski e Zanin (2003) e Giongo e Waechter (2004) e em Santa Catarina o trabalho inédito de epífitos vasculares de Caglioni et al. (2012) que abrange todas as tipologias florestais do estado. Segundo esses últimos autores, até então este grupo de plantas tinha sido estudado apenas de modo parcial, enfocando-se famílias botânicas específicas como, por exemplo, Bromeliaceae, Araceae, Cactaceae, Orchidaceae e o grupo das pteridófitas.

A grande maioria de estudos em florestas realizados no Brasil se baseia em árvores e, via de regra, as comunidades são conhecidas pelas espécies arbóreas que as compõem, e pouco se sabe sobre as outras formas de vida não arbóreas, como os epífitos.

Embora o número de estudos com os epífitos vasculares venham crescendo, o presente estudo contribui efetivamente para o conhecimento desta forma de vida no sul de Santa Catarina, onde os epífitos têm sido quase sempre omitidos em estudos florísticos.

Neste contexto, este estudo se propôs a analisar a riqueza específica, a estrutura e a distribuição espacial vertical de epífitos vasculares na Floresta Ombrófila Densa, localizada no Parque Estadual da Serra Furada, no sul do estado de Santa Catarina.

\section{Material e métodos}

A área de estudo pertence ao Parque Estadual da Serra Furada (PESF), ocupando parte dos territórios dos municípios de Grão Pará e Orleans. Possui uma área de 1.330 ha e está localizado no Sul do estado de Santa Catarina, nas coordenadas $49^{\circ} 25^{\prime} 17^{\prime \prime}$ e $49^{\circ} 22^{\prime} 58^{\prime \prime}$ de longitude Oeste e $28^{\circ} 08^{\prime} 13^{\prime \prime}$ e $28^{\circ} 11^{\prime} 36^{\prime \prime}$ de latitude Sul (sede do Parque) em altitudes que variam de 400 a 1.480 m (FATMA, 2009).

O clima em regiões de menor altitude, de acordo com Köppen, é subtropical úmido, sem estação seca e com verão quente (Cfa). A temperatura média anual varia entre 18,8 a $19,2{ }^{\circ} \mathrm{C}$, sendo a temperatura máxima de $35{ }^{\circ} \mathrm{C}$ e a temperatura mínima de $-5{ }^{\circ} \mathrm{C}$. A precipitação total anual está entre 1.300 e $1.600 \mathrm{~mm}$, com geadas constantes no inverno (EPAGRI, 2001).

As incursões para o estudo da comunidade epifítica vascular foram realizadas entre junho de 2010 e maio de 2012. Para o levantamento estrutural, cada árvore foi considerada uma unidade amostral, definida pelo método de quadrantes (COTTAM; CURTIS, 1956), sendo estabelecidos seis transectos no PESF. Para cada transecto foram determinados cinco pontos quadrantes, separados $20 \mathrm{~m}$ entre si, totalizando 120 unidades amostrais, com $\mathrm{DAP} \geq 10 \mathrm{~cm}$.

Cada forófito amostrado no levantamento foi caracterizado quanto à aspereza e persistência da casca, seguindo a classificação proposta por Waechter (1992), qual seja: lisa, áspera, rugosa e fissurada, podendo ainda ser classificada em persistente ou descamante 
(HOELTGEBAUM, 2003). Essa metodologia foi aplicada para analisar a preferência dos epífitos vasculares por padrões de casca.

Para caracterizar a distribuição vertical dos epífitos vasculares nos diferentes intervalos de altura no forófito, seguiu-se proposta de zonação adaptada de Johansson (1974), que divide o forófito em regiões conforme sua estrutura. Neste estudo, os forófitos foram divididos em fuste e copa, considerando copa como o ponto do qual emergem os ramos principais. A ocorrência das espécies epifíticas no fuste e na copa foi registrada quanto à presença (1) ou ausência (0) das espécies e foram calculadas as frequências relativas percentuais por copas (FRci $=\mathrm{Nci} / \Sigma \mathrm{Nci})$ e por fustes $($ FRfi $=\mathrm{Nfi} / \Sigma \mathrm{Nfi})($ GIONGO; WAECHTER, 2004).

Foram calculadas, para as espécies epifíticas amostradas, as frequências absolutas e relativas, de acordo com Mueller-Dombois e Ellenberg (2002).

O registro dos epífitos vasculares foi obtido por meio de uso de binóculo, com visualização a partir do solo ou de árvores vizinhas ou ainda por meio de uma escada telemétrica de 3,8 metros de comprimento. O reconhecimento e identificação das espécies teve como base Hoehne (1942, 1945, 1949, 1953), Pabst e Dungs (1975, 1977), Reitz (1983), Tamashiro e Zickel (1991), Guimarães (1998), Coelho (2000), Wanderley et al. (2007) e Azeredo e Citadini-Zanette (2012). As espécies quando não identificadas pela literatura disponível, foram encaminhadas para especialistas e algumas, por se encontrarem em estado vegetativo, não foi possível a identificação em nível específico.

Para as famílias botânicas das angiospermas foi adotado o sistema de classificação APG III (2009) e para samambaias Smith et al. (2006). Para caracterizar floristicamente a comunidade epifítica vascular do PESF, foi utilizado também o método expedito por caminhamento (FILGUEIRAS et al., 1994), visando registrar as espécies não incluídas na amostragem.

O material fértil coletado foi herborizado, identificado e incorporado ao Herbário Pe. Raulino Reitz (CRI) da Universidade do Extremo Sul Catarinense (UNESC), Criciúma, Santa Catarina. Os exemplares coletados em estado vegetativo foram depositados no Herbário CRI, visando a comparações futuras com material fértil. Estes exemplares não constam no acervo com número de voucher.

As espécies foram classificadas em categorias ecológicas, conforme Benzing (1990) e quanto à biologia reprodutiva (polinização e dispersão) estabelecidas com base na literatura (FISCHER; ARA ÚJO, 1995; SANTOS, 2000; BORGO; SILVA, 2003; HEFLER; FAUSTIONI, 2004; BREIER, 2005; DETTKE et al., 2008; SANTOS, 2008; CAGLIONI et al., 2012).

Para análise da heterogeneidade florística da área estudada foram utilizados os índices de Shannon $\left(\mathrm{H}^{\prime}\right)$ para obtenção da diversidade específica (alfa) e de equabilidade (J) de acordo com Magurran (1988) e Pielou
(1975), respectivamente.

Foi utilizado o teste $\chi^{2}$, ao nível de significância de 5\% (ZAR, 1999; CALLEGARI-JACQUES, 2003), para determinar diferenças entre frequência observada e esperada dos epífitos nas duas zonas verticais propostas (fuste e copa). Os valores esperados de cada espécie epifítica foram obtidos dividindo-se por dois a frequência observada sobre indivíduos forofíticos. As espécies que obtiveram frequências esperadas inferiores a cinco não foram consideradas. Foi aplicado a correção de Yates $(-0,5)$ ao teste $\chi^{2}$.

A relação entre o número de espécies epifíticas e o diâmetro do forófito foi testada através de análise de correlação de Spearman (ZAR, 1999), ao nível de significância a 5\%. A análise foi realizada com o auxílio do software PAST, versão 1.89 (HAMMER; HARPER; RYAN, 2009).

\section{Resultados e discussão}

Foram registradas 115 espécies epifíticas, distribuídas em 59 gêneros e em 20 famílias (Tabela 1). Do total de espécies, 85 foram amostradas no levantamento fitossociológico, e as demais (30 espécies) no levantamento florístico, através do método por caminhamento. A família que apresentou maior riqueza específica foi Orchidaceae (38 espécies), seguida de Bromeliaceae com 23 espécies, Polypodiaceae com 14, Araceae e Cactaceae com seis espécies. As demais famílias apresentaram número variável de espécies, por cinco até uma espécie. Os gêneros com maior diversidade foram Vriesea, representado por dez espécies, Epidendrum por seis, Peperomia e Tillandsia por cinco. Nas demais famílias, os gêneros variaram, de quatro a uma espécie.

Orchidaceae, Bromeliaceae e Polypodiaceae se destacaram como as famílias mais numerosas, com $65 \%$ das espécies encontradas no estudo, confirmando serem as famílias mundialmente mais ricas da flora epifítica (MADISON, 1977; KRESS, 1986; BENZING, 1990). No Brasil, estudos realizados na Floresta Ombrófila Densa apresentaram as mesmas famílias como as de maior riqueza específica (WAECHTER, 1992; BUZZATO et al., 2008; PETEAN, 2009; BLUM et al., 2011; BIANCHI et al., 2012; OLIVEIRA et al., 2013), bem como em outras formações (WAECHTER, 1998; PERLEBERG et al., 2013). Kersten (2010) aponta essas três famílias como as mais abundantes, atribuindo o sucesso de Orchidaceae ao fato de cerca de duas em cada três de suas espécies serem epífitas, ao passo que em Bromeliaceae, aproximadamente $50 \%$ de suas espécies vivem acima do solo e Polypodiaceae é basicamente de hábito epifítico.

Orchidaceae é praticamente a família mais rica na maioria dos estudos (ROGALSKI; ZANIN, 2003; BORGO; SILVA, 2003; GIONGO; WAECHTER, 2004; KERSTEN; WAECHTER, 2011), independente de pluviosidade (DISLICH; MANTOVANI, 1998), 
Tabela 1 - Relação dos epífitos vasculares encontrados no Parque Estadual da Serra Furada, sul de Santa Catarina, onde: categoria ecológica (CE): holoepífito verdadeiro (HLV), holoepífito facultativo (HLF), holoepífito acidental (HLA), hemiepífito primário (HMP) e sem informação (SI). Polinização (P): ornitofilia (OR), entomofilia $(E N)$ e anemofilia (AF). Dispersão (D): anemocoria (AN), pogonocoria (PO), autocoria (AU) e epizoocoria (EP). Voucher $(\mathrm{V})$ : número do registro de material fértil tombado no Herbário CRI. *Espécie registrada somente no levantamento florístico.

\begin{tabular}{|c|c|c|c|c|}
\hline Família/Espécie & $\mathrm{CE}$ & $\mathbf{P}$ & D & $\mathbf{V}$ \\
\hline \multicolumn{5}{|l|}{ Amaryllidaceae } \\
\hline Hippeastrum aulicum Herb. & HLF & EN & AN & \\
\hline \multicolumn{5}{|l|}{ Araceae } \\
\hline Anthurium gaudichaudianum Kunth & HLV & EN & $\mathrm{ZO}$ & \\
\hline Anthurium scandens (Aubl.) Engl.* & HLV & EN & $\mathrm{ZO}$ & \\
\hline Anthurium sp. & SI & EN & $\mathrm{ZO}$ & \\
\hline Philodendron appendiculatum Nadruz \& S.J. Mayo & HMP & EN & $\mathrm{ZO}$ & \\
\hline Philodendron missionum (Hauman) Hauman* & HMS & EN & $\mathrm{ZO}$ & \\
\hline Philodendron sp. & SI & EN & $\mathrm{ZO}$ & \\
\hline \multicolumn{5}{|l|}{ Arecaceae } \\
\hline Euterpe edulis Mart. & HLA & EN & $\mathrm{ZO}$ & \\
\hline \multicolumn{5}{|l|}{ Aspleniaceae } \\
\hline Asplenium harpeodes Kunze* & HLV & - & AN & \\
\hline Asplenium scandicinum Kaulf. & HLV & - & AN & \\
\hline \multicolumn{5}{|l|}{ Begoniaceae } \\
\hline Begonia biguassuensis Brade & HMS & EN & SI & \\
\hline \multicolumn{5}{|l|}{ Blechnaceae } \\
\hline Blechnum binervatum (Poir.) C.V. Morton \& Lellinger & HMS & - & AN & \\
\hline \multicolumn{5}{|l|}{ Bromeliaceae } \\
\hline Aechmea calyculata (E.Morren) Baker* & HLF & OR & $\mathrm{ZO}$ & 10491 \\
\hline Aechmea caudata Lindm & HLV & OR & $\mathrm{ZO}$ & \\
\hline Aechmea nudicaulis (L.) Griseb.* & HLV & OR & $\mathrm{ZO}$ & \\
\hline Billbergia nutans H. Wendl. ex Regel & HLV & OR & $\mathrm{PO}$ & 10500 \\
\hline Edmundoa lindenii (Regel) Leme & HLV & OR - EN & $\mathrm{ZO}$ & \\
\hline Nidularium innocentii Lem. & HLF & OR & $\mathrm{ZO}$ & \\
\hline Nidularium procerum Lindm.* & HLF & OR & $\mathrm{ZO}$ & \\
\hline Tilladsia usneoides (L.) L. & HLV & OR & $\mathrm{PO}$ & 10493 \\
\hline Tillandsia aeranthos (Loisel.) L.B. Sm. & HLV & OR & $\mathrm{PO}$ & 10497 \\
\hline Tillandsia geminiflora Brongn. & HLV & OR - EN & $\mathrm{PO}$ & 10496 \\
\hline Tillandsia mallemontii Glaz. ex Mez & HLV & OR & $\mathrm{PO}$ & \\
\hline Tillandsia stricta Sol. ex Sims & HLV & OR - EN & $\mathrm{PO}$ & \\
\hline Vriesea carinata Wawra & HLV & OR & $\mathrm{PO}$ & 10498 \\
\hline Vriesea erythrodactylon (E.Morren) E. Morren ex Mez* & HLV & OR & $\mathrm{PO}$ & 10499 \\
\hline Vriesea flammea L.B. Sm. & HLV & OR & $\mathrm{PO}$ & 10495 \\
\hline Vriesea guttata Linden \& André* & HLV & OR & $\mathrm{PO}$ & \\
\hline Vriesea incurvata Gaudich. & HLV & OR & $\mathrm{PO}$ & 10492 \\
\hline Vriesea philippocoburgii Wawra* & HLV & OR & $\mathrm{PO}$ & 10490 \\
\hline Vriesea platynema Gaudich. & HLV & OR & $\mathrm{PO}$ & \\
\hline Vriesea psittacina (Hook.) Lindl.* & HLV & OR & $\mathrm{PO}$ & \\
\hline Vriesea scalaris E. Morren* & HLV & OR & $\mathrm{PO}$ & 10489 \\
\hline Vriesea vagans (L.B. Sm.) L.B. Sm. & HLV & OR & $\mathrm{PO}$ & 10494 \\
\hline Wittrockia superba Lindm. & HLV & OR & $\mathrm{ZO}$ & \\
\hline \multicolumn{5}{|l|}{ Cactaceae } \\
\hline Lepismium cruciforme (Vell.) Miq. & HLV & EN & $\mathrm{ZO}$ & \\
\hline Lepismium houlletianum (Lem.) Barthlott & HLV & EN & $\mathrm{ZO}$ & \\
\hline Rhipsalis pachyptera Pfeiff. & HLV & EN & $\mathrm{ZO}$ & \\
\hline Rhipsalis paradoxa (Salm-Dyck ex Pfeiff.) Salm-Dyck & HLV & EN & $\mathrm{ZO}$ & \\
\hline Rhipsalis teres (Vell.) Steud. & HLV & EN & $\mathrm{ZO}$ & \\
\hline Rhipsalis trigona Pfeiff. & HLV & EN & $\mathrm{ZO}$ & \\
\hline \multicolumn{5}{|l|}{ Clusiaceae } \\
\hline Clusia criuva Cambess. & HMP & EN & $\mathrm{ZO}$ & \\
\hline
\end{tabular}


Tabela 1 - continuação...

\begin{tabular}{|c|c|c|c|c|}
\hline Família/Espécie & $\mathrm{CE}$ & $\mathbf{P}$ & D & $\mathbf{V}$ \\
\hline \multicolumn{5}{|l|}{ Dryopteridaceae } \\
\hline $\begin{array}{l}\text { Elaphoglossum glaziovii (Fée) Brade. } \\
\text { Elaphoglossum lingua (C. Presl) Brack }\end{array}$ & $\begin{array}{l}\text { HLV } \\
\text { HLF }\end{array}$ & $\begin{array}{l}- \\
-\end{array}$ & $\begin{array}{l}\text { AN } \\
\text { AN }\end{array}$ & \\
\hline \multicolumn{5}{|l|}{ Gesneriaceae } \\
\hline $\begin{array}{l}\text { Codonanthe cordifolia Chautems* } \\
\text { Codonanthe devosiana Lem. } \\
\text { Nematanthus australis Chautems } \\
\text { Nematanthus tessmanii (Hoehne) Chautems } \\
\text { Sinningia douglasii (Lindl.) Chautems }\end{array}$ & $\begin{array}{l}\text { HLV } \\
\text { HLV } \\
\text { HLV } \\
\text { HLV } \\
\text { HLV }\end{array}$ & $\begin{array}{l}\text { EN } \\
\text { EN } \\
\text { OR } \\
\text { OR } \\
\text { OR }\end{array}$ & $\begin{array}{l}\text { AU } \\
\text { AU } \\
\text { AU } \\
\text { AU } \\
\text { AN }\end{array}$ & 10503 \\
\hline \multicolumn{5}{|l|}{ Hymenophyllaceae } \\
\hline $\begin{array}{l}\text { Hymenophyllum asplenioides (Sw.) Sw. } \\
\text { Hymenophyllum caudiculatum Mart. }\end{array}$ & $\begin{array}{l}\text { HLV } \\
\text { HLV }\end{array}$ & $\overline{-}$ & $\begin{array}{l}\text { AN } \\
\text { AN }\end{array}$ & \\
\hline \multicolumn{5}{|l|}{ Lycopodiaceae } \\
\hline $\begin{array}{l}\text { Huperzia heterocarpon (Fée) Holub* } \\
\text { Huperzia mandiocana (Raddi) Trevis. } \\
\text { Monimiaceae }\end{array}$ & $\begin{array}{l}\text { HLV } \\
\text { HLV }\end{array}$ & - & $\begin{array}{l}\text { AN } \\
\text { AN }\end{array}$ & \\
\hline Mollinedia schottiana (Spreng.) Perkins & HLA & $\mathrm{EN}$ & $\mathrm{ZO}$ & \\
\hline \multicolumn{5}{|l|}{ Orchidaceae } \\
\hline $\begin{array}{l}\text { Acianthera glanduligera (Lindl.) Luer } \\
\text { Acianthera sp. } \\
\text { Alatiglossum longipes (Lindl.) Baptista } \\
\text { Anathallis sp.* } \\
\text { Baptistonia sp. } \\
\text { Bifrenaria cf. harrisoniae (Hook.) Rchb. f. } \\
\text { Bifrenaria sp.1 } \\
\text { Bifrenaria sp.2* }\end{array}$ & $\begin{array}{l}\text { HLV } \\
\text { HLV } \\
\text { HLV } \\
\text { HLV } \\
\text { HLV } \\
\text { HLV } \\
\text { HLV } \\
\text { HLV }\end{array}$ & $\begin{array}{l}\text { EN } \\
\text { EN } \\
\text { EN } \\
\text { EN } \\
\text { EN } \\
\text { EN } \\
\text { EN }\end{array}$ & $\begin{array}{l}\text { AN } \\
\text { AN } \\
\text { AN } \\
\text { AN } \\
\text { AN } \\
\text { AN } \\
\text { AN } \\
\text { AN }\end{array}$ & 10481 \\
\hline Brasiliorchis porphyrostele (Rchb. f.) R.B. Singer, S. Koehler \& Carnevali & HLV & EN & AN & 10505 \\
\hline Brasiliorchis marginata (Lindl.) R.B. Singer, S. Koehler \& Carnevali & HLV & EN & AN & \\
\hline $\begin{array}{l}\text { Bulbophyllum sp. } \\
\text { Campylocentrum aromaticum Barb. Rodr. }\end{array}$ & $\begin{array}{l}\text { HLV } \\
\text { HLV }\end{array}$ & $\begin{array}{l}\text { EN } \\
\text { EN }\end{array}$ & $\begin{array}{l}\text { AN } \\
\text { AN }\end{array}$ & \\
\hline Campylocentrum sellowii (Rchb. f.) Rolfe & HLV & EN & AN & 10477 \\
\hline Coppensia flexuosa (Lodd.) Campacci & HLV & $\mathrm{EN}$ & AN & \\
\hline Cyclopogon elatus (Sw.) Schltr. & HLF & $\mathrm{EN}$ & AN & \\
\hline Dichaea cogniauxiana Schltr. & $\mathrm{HLV}$ & $\mathrm{EN}$ & AN & 10483 \\
\hline Dichaea pendula (Aubl.) Cogn. & HLV & $\mathrm{EN}$ & AN & 10478 \\
\hline Epidendrum cf. paniculatum Ruiz \& Pav. & HLV & $\mathrm{EN}$ & AN & 10480 \\
\hline Epidendrum cf. pseudodifforme Hoehne \& Schltr. & HLV & EN & AN & \\
\hline Epidendrum cf. ramosum Jacq. & HLV & EN & AN & \\
\hline Epidendrum secundum Jacq. ${ }^{*}$ & HLV & EN & AN & \\
\hline Epidendrum vesicatum Lindl. & HLV & EN & AN & \\
\hline Epidendrum sp. & HLV & EN & AN & \\
\hline Gomesa crispa (Lindl.) Klotzsch ex Rchb. f.* & HLV & $\mathrm{EN}$ & AN & \\
\hline Isochilus linearis (Jacq.) R. Br.* & HLV & $\mathrm{EN}$ & AN & 10482 \\
\hline Lankesterella caespitosa Hoehne & HLV & $\mathrm{EN}$ & AN & 10476 \\
\hline Octomeria cf. crassifolia Lindl. & HLV & EN & AN & \\
\hline Octomeria cf. grandiflora Lindl.* & HLV & EN & AN & \\
\hline Octomeria sp. & HLV & $\mathrm{EN}$ & AN & 10486 \\
\hline Pabstiella hypnicola (Lindl.) Luer & HLV & $\mathrm{EN}$ & $\mathrm{AN}$ & \\
\hline Phymatidium sp.* & HLV & $\mathrm{EN}$ & $\mathrm{AN}$ & 10488 \\
\hline Polystachya concreta (Jacq.) Garay \& H.R. Sweet & HLV & EN & $\mathrm{AN}$ & \\
\hline Promenaea riograndensis Schltr. & HLV & EN & $\mathrm{AN}$ & \\
\hline Prosthechea vespa (Vell.) W.E. Higgins* & HLV & $\mathrm{EN}$ & $\mathrm{AN}$ & \\
\hline Stelis megantha Barb. Rodr. & HLV & EN & $\mathrm{AN}$ & \\
\hline Stelis intermedia Poepp. \& Endl.* & HLV & EN & $\mathrm{AN}$ & 10484 \\
\hline Stelis pauciflora Lindl. ${ }^{*}$ & HLV & EN & AN & 10487 \\
\hline Stelis sp. & HLV & EN & $\mathrm{AN}$ & 10485 \\
\hline
\end{tabular}


Tabela 1 - continuação...

\begin{tabular}{|c|c|c|c|c|}
\hline Família/Espécie & CE & $\mathbf{P}$ & $\mathbf{D}$ & $\mathbf{V}$ \\
\hline \multicolumn{5}{|l|}{ Piperaceae } \\
\hline $\begin{array}{l}\text { Peperomia catharinae Miq. } \\
\text { Peperomia cf. urocarpa Fisch. \& C.A. Mey.* } \\
\text { Peperomia pereskiifolia (Jacq.) Kunth } \\
\text { Peperomia sp.* } \\
\text { Peperomia tetraphylla Hook. \& Arn. }\end{array}$ & $\begin{array}{l}\text { HLV } \\
\text { HLF } \\
\text { HLF } \\
\text { SI } \\
\text { HLV }\end{array}$ & $\begin{array}{l}\mathrm{AF} \\
\mathrm{AF} \\
\mathrm{AF} \\
\mathrm{AF} \\
\mathrm{AF}\end{array}$ & $\begin{array}{l}\mathrm{ZO} \\
\mathrm{ZO} \\
\mathrm{ZO} \\
\mathrm{ZO} \\
\mathrm{ZO}\end{array}$ & 10501 \\
\hline Polypodiaceae & & & & 10502 \\
\hline $\begin{array}{l}\text { Alansmia reclinata (Brack.) Moguel \& M. Kessler* } \\
\text { Campyloneurum acrocarpon Fée } \\
\text { Campyloneurum minus Fée* } \\
\text { Campyloneurum nitidum (Kaulf.) C. Presl } \\
\text { Lellingeria depressa (C. Chr.) A.R. Sm. \& R.C. Moran* } \\
\text { Microgramma squamulosa (Kaulf.) de la Sota } \\
\text { Microgramma vacciniifolia (Langsd. \& Fisch.) Copel } \\
\text { Niphidium crassifolium (L.) Lellinger } \\
\text { Pecluma paradiseae (Langsd. \& Fisch.) M.G. Price } \\
\text { Pecluma truncorum (Lindm.) M.G. Price } \\
\text { Pleopeltis hirsutissima (Raddi) de la Sota } \\
\text { Pleopeltis pleopeltifolia (Raddi) Alston } \\
\text { Polypodium sp. } \\
\text { Serpocaulon catharinae (Langsd. \& Fisch.) A.R. Sm. }\end{array}$ & $\begin{array}{l}\text { HLV } \\
\text { HLF } \\
\text { HLV } \\
\text { HLV } \\
\text { HLV } \\
\text { HLV } \\
\text { HLV } \\
\text { HLV } \\
\text { HLV } \\
\text { HLV } \\
\text { HLV } \\
\text { HLV } \\
\text { HLV } \\
\text { HLV }\end{array}$ & $\begin{array}{l}- \\
- \\
- \\
- \\
- \\
- \\
- \\
- \\
- \\
- \\
- \\
-\end{array}$ & $\begin{array}{l}\text { AN } \\
\text { AN } \\
\text { AN } \\
\text { AN } \\
\text { AN } \\
\text { AN } \\
\text { AN } \\
\text { AN } \\
\text { AN } \\
\text { AN } \\
\text { AN } \\
\text { AN } \\
\text { AN } \\
\text { AN }\end{array}$ & \\
\hline \multicolumn{5}{|l|}{ Pteridaceae } \\
\hline Vittaria lineata (L.) Sm. & HLV & - & AN & \\
\hline \multicolumn{5}{|l|}{ Rubiaceae } \\
\hline $\begin{array}{l}\text { Hillia parasitia Jacq.* } \\
\text { Rudgea jasminoides (Cham.) Müll. Arg. }\end{array}$ & $\begin{array}{l}\text { HMP } \\
\text { HLA }\end{array}$ & $\begin{array}{l}\text { EN } \\
\text { EN }\end{array}$ & $\begin{array}{l}\mathrm{ZO} \\
\mathrm{ZO}\end{array}$ & \\
\hline \multicolumn{5}{|l|}{ Selaginellaceae } \\
\hline Selaginella sp. & HLA & - & AN & \\
\hline
\end{tabular}

e também a que mais atrai por sua beleza. Por isso, em áreas de fácil acesso, elas podem sofrer exploração por meio de coletas indiscriminadas, e a retirada de orquídeas de seu ambiente natural vem aumentando devido a diversos fatores como a urbanização, aumento de atividades agrícolas e extrativismo predatório (MENEZES, 1985, 1987). Orchidaceae embora mais rica, normalmente não se mantém como a mais abundante, pois a retirada predatória pode afetar diretamente sua riqueza (MORAES et al., 2009).

Pelo escasso conhecimento técnico-científico associado, a ação predatória também ocorre em Bromeliaceae pelo interesse deste grupo de plantas como ornamentais devido à rusticidade, beleza e duração de suas flores (NEGRELLE; MURARO, 2006).

Segundo Moran (1995), Polypodiaceae é cosmopolita e uma das maiores famílias de pteridófitas, o que pode explicar a representatividade de suas espécies como plantas ornamentais, como é o caso de Campyloneurum rigidum, que é endêmica de alguns estados brasileiros (MACEDO; NONATO, 2009). Estes autores destacam que é fator imprescindível, a propagação de tais espécies em locais legalizados como forma de evitar a pressão por coletas na natureza.
As espécies de Orchidaceae, Bromeliaceae e Polypodiaceae, pelo acima exposto, encontram-se vulneráveis na natureza o que requer atenção redobrada para manter suas inegáveis funções no ecossistema.

A riqueza florística observada no PESF pode ser considerada alta quando comparada com outros estudos realizados no sul do Brasil (Tabela 2), sendo menor apenas quando comparada a quatro outras áreas.

A maior riqueza encontrada nesses levantamentos (Tabela 2) pode estar relacionada com o grau de conservação destes ambientes, já que a maioria das áreas com maior riqueza é de florestas primárias pouco alteradas, enquanto que parte da área do PESF sofreu intervenção humana em épocas passadas e possui zonas de conflitos no entorno, que historicamente retrata extração seletiva de madeira e de outros produtos florestais não madeireiros, como o palmito-juçara (Euterpe edulis Mart.), formação de pastagens para o gado, bananicultura e silvicultura de Eucalyptus e Pinus, além de sinais de ação antrópica, como caminhadas desordenadas, deixando solo exposto, marcas nos caules, lixo, marcas de pneus, vestígios de fogueiras e pichações nos paredões. 
Tabela 2 - Comparação entre estudos realizados no Bioma Mata Atlântica e ecossistemas associados com epífitos vasculares no Sul do Brasil, onde: Floresta Estacional Semidecidual (FES), Floresta Ombrófila Densa (FOD),

Floresta Ombrófila Mista (FOM), Restinga (RES).

\begin{tabular}{|c|c|c|c|c|c|c|}
\hline Formação & Localidade & UF & Espécie & Gênero & Família & Fonte \\
\hline FOD & Serra da Prata & PR & 277 & 109 & 30 & Blum et al. (2011) \\
\hline $\mathrm{FOD}$ & Guaraqueçaba & PR & 176 & 79 & 30 & Schutz-Gatti (2000) \\
\hline FOD & Antonina & PR & 159 & 78 & 22 & Petean (2009) \\
\hline FOD/FOM & Piraquara & PR & 140 & 64 & 26 & Kersten (2006) \\
\hline FODM & Orleans/Grão Pará & SC & 115 & 59 & 20 & Este estudo \\
\hline \multirow[t]{2}{*}{ RES } & Torres I & RS & 115 & 56 & 15 & Waechter (1986) \\
\hline & Primeiro Planalto & & & & & Kersten e Kuniyoshi \\
\hline FOM & Paranaense & PR & 114 & 52 & 20 & (2009) \\
\hline RES & Ilha do Mel & PR & 103 & 49 & 20 & Kersten e Silva (2006) \\
\hline FOD/FOM & Piraquara & PR & 101 & 54 & 20 & Hertel (1949) \\
\hline FOD & Marumbi & PR & 97 & 49 & 16 & Petean (2002) \\
\hline FOM & Curitiba & PR & 96 & 48 & 21 & Borgo e Silva (2003) \\
\hline RES & Torres II & RS & 93 & 44 & 15 & Waechter (1992) \\
\hline \multirow[t]{2}{*}{ RES } & Ilha do Mel & PR & 77 & 44 & 17 & Kersten e Silva (2001) \\
\hline & & & & & & Gonçalves e Waechter \\
\hline RES & Terra de Areia & RS & 77 & 33 & 10 & (2003) \\
\hline FOM & Curitiba & PR & 72 & 41 & 18 & Dittrich et al. (1999) \\
\hline FES & Marcelino Ramos & RS & 70 & 30 & 8 & Rogalski e Zanin (2003) \\
\hline FOD & Criciúma & SC & 65 & 39 & 14 & Oliveira et al. (2013) \\
\hline \multirow[t]{2}{*}{ FES } & Pelotas & $\mathrm{RS}$ & 63 & 31 & 9 & Perleberg et al. (2013) \\
\hline & & & & & & Giongo e Waechter \\
\hline FES & Eldorado do Sul & RS & 57 & 34 & 15 & (2004) \\
\hline \multirow[t]{2}{*}{ FES } & Foz do Iguaçu & PR & 56 & 38 & 13 & Cerví e Borgo (2007) \\
\hline & Guarapuava e & & & & & \\
\hline FOM & Pinhão & PR & 54 & 32 & 13 & Kersten et al. (2009) \\
\hline FOM & Araucária & PR & 49 & 28 & 12 & Kersten e Silva (2002) \\
\hline FES & Fênix & PR & 32 & 23 & 10 & Borgo et al. (2002) \\
\hline \multirow[t]{2}{*}{ RES } & Taim & RS & 24 & 17 & 8 & Waechter (1992) \\
\hline & Maximiliano de & & & & & \\
\hline FOM & Almeida & RS & 18 & 12 & 7 & Bataghin et al. (2008) \\
\hline FES & Montenegro/Triunfo & RS & 17 & 12 & 4 & Aguiar et al. (1981) \\
\hline
\end{tabular}

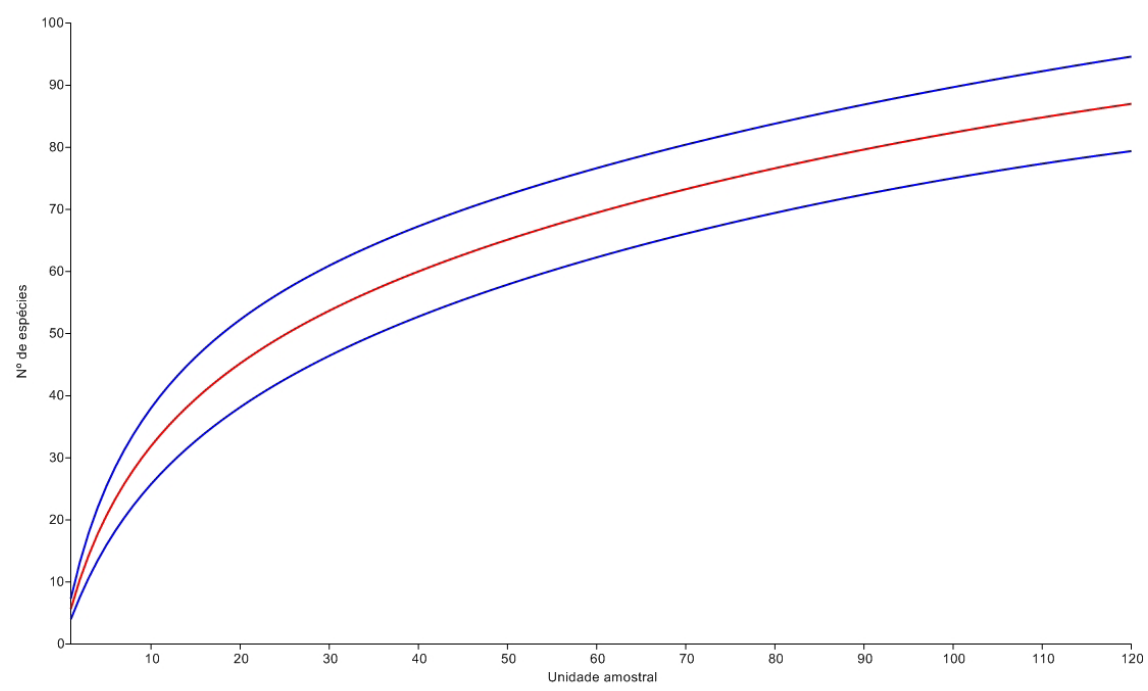

Figura 1 - Curva de rarefação estimada (curva central) para as espécies epifíticas vasculares do PESF e seus intervalos de confiança (+95\% e $-95 \%)$. 
Embora apresente influências antrópicas negativas na Floresta Ombrófila Densa, é possível inferir que a área do PESF ainda detém grande número de espécies vegetais e de hábitos bastante variados.

Quanto à representatividade florística da área em estudo, a curva de rarefação indica tendência à estabilização (Figura 1), considerando que com metade da amostra (60 forófitos), cerca de $82 \%$ das espécies epifíticas foram amostradas, evidenciando que a amostragem foi considerada adequada para este estudo.

Na categoria ecológica, 94 espécies $(81,7 \%)$ são holoepífitos verdadeiros, nove $(7,8 \%)$ são holoepífitos facultativos, quatro $(3,5 \%)$ são holoepífitos acidentais, três $(2,6 \%)$ são holoepífitos primários, três $(2,6 \%)$ são holoepífitos secundários e para duas espécies $(1,8 \%)$ não foi possível a identificação (Tabela 1). A grande representatividade de holoepífitos verdadeiros é comum, sendo geral tanto no Brasil quanto em quase todo o mundo (WAECHTER, 1986; DITTRICH et al., 1999; KERSTEN; SILVA, 2001; GIONGO; WAECHTER, 2004; KERSTEN; KUNIYOSHI, 2009; CAGLIONI et al., 2012; OLIVEIRA et al., 2013). A predominância desse grupo se dá pelas adaptações vegetativas especializadas e diversificadas, favorecendo assim, uma distribuição mais generalizada nas formações florestais, tornando os holoepífitos verdadeiros amplamente distribuídos em todo globo terrestre (STAUDT et al., 2012).

Quanto às estratégias reprodutivas, na polinização 62 espécies são entomófilas (66,7\%), 26 ornitófilas $(27,9)$ e cinco anemófilas (5,4\%). Neste contexto, Orchidaceae e Araceae se destacaram pelas muitas espécies entomófilas e, Bromeliaceae, pelas espécies ornitófilas.

É notória a importância dos fatores bióticos na polinização, como destacado por Gentry e Dodson (1987), tendo os animais uma importante participação para os epífitos vasculares. A entomofilia como estratégia prevalente, tem sido apontada em outros estudos do epifitismo, sendo as abelhas seu principal vetor polinizador (MADISON, 1977; BREIER, 2005; OLIVEIRA et al., 2013). Salienta-se que Bromeliaceae é uma das poucas famílias onde a polinização por vertebrados predomina sobre a entomofilia (SAZIMA; VOGEL; SAZIMA, 1989).

Entre as estratégias de dispersão, a anemocoria foi registrada em 65 espécies (56,5\%), seguida de zoocoria com $29(25,2 \%)$, pogonocoria com $16(13,9 \%)$, que é um tipo de anemocoria, caracterizada pela presença de sementes aladas ou plumosas (KERSTEN, 2010), autocoria com quatro (3,5\%) e uma espécie $(0,9 \%)$ sem informação. A frequência de espécies anemocóricas é enfatizada também em outros estudos de epifitismo (DITTRICH et al., 1999; GONÇALVES; WAECHTER, 2003; BREIER, 2005; OLIVEIRA et al., 2013).

As espécies epifíticas com dispersão pelo vento são favorecidas pelo fato de suas sementes diminutas possuirem estruturas pequenas que permitem colonizar facilmente, percorrendo distâncias maiores até encontrar um local para fixação, sem necessidade de animais como dispersores (NIEDER et al., 1996). Orchidaceae com suas sementes na forma de um pó fino, Bromeliacae com suas diferenciações morfológicas em sementes, com apêndices plumosos e pteridófitas com seus diminutos esporos são exemplos desse tipo de dispersão (KERSTEN, 2010). Tryon (1970) salienta que para as pteridófitas, a dispersão de seus esporos pelo vento pode ultrapassar barreiras geográficas, cadeias de montanhas e grandes porções oceânicas.

O número de espécies epifíticas variou de zero a 21 nas árvores amostradas. O indivíduo com maior registro (21 espécies epifíticas) apresentou DAP de 58,6 cm, 15 metros de altura, com ritidoma rugoso e persistente. Os fatores que facilitam a fixação e estabilização de propágulos nas árvores fortalecem a relação entre forófito e epífitos, pois nessas árvores, há grande retenção de água, que promove uma relação maior, além de favorecer aderência dos diásporos (STEEGE; CORNELISSEN, 1989).

O tipo de ritidoma mais frequente foi o áspero (68), seguido de rugoso (26), liso (18) e fissurado (oito), destes, 112 persistentes e oito descamantes.

Os ritidomas do tipo áspero e rugoso foram também predominantes em outro trabalho no sul do Brasil (WAECHTER, 1992). Bonnet e Queiroz (2006), em estudo com bromélias epifíticas, abordam o ritidoma liso e descamante como substrato com pouca estabilidade, já que esse tipo de casca desprende-se em placas e muitas vezes o propágulo não pode se estabilizar. No presente estudo, um forófito descamante com DAP de 75,8 cm teve 19 espécies registradas, sendo 15 somente na copa, duas no fuste e duas no fuste e copa. Bonnet et al. (2007) consideram importante, em seu estudo com bromélias epífitas, uma espécie forofítica com ritidoma liso, porém, as bromélias foram colonizadas a partir da copa, sugerindo que as bifurcações podem sustentar os epífitos, além do tamanho e tempo do substrato disponível.

No levantamento estrutural, as espécies que tiveram maior valor de importância foram Nidularium innocentii e Vriesea incurvata (Tabela 3). Nidularium innocentii normalmente se encontra nas regiões mais baixas da árvore e, neste sentido sua frequencia no fuste foi muito superior à copa. Essa espécie é adaptada a desenvolver em áreas sombreadas e no interior de floresta, podendo por vezes também formar um tapete. Caglioni et al. (2012) também apontam $N$. innocentii e $V$. incurvata entre as dez espécies predominantes mais frequentes.

Das dez espécies com maiores valores de importância no presente estudo, quatro pertencem ao gênero Vriesea, corroborando com Waechter (1986) e Breier (2005). Martinelli et al. (2008) apontam Vriesea como o gênero de maior riqueza de bromeliáceas da Mata Atlântica.

No total, 21 espécies foram registradas somente uma vez em um único forófito (11 no fuste e 10 na copa), podendo se inferir que as espécies estão iniciando a colonização nos forófitos ou são raras na comunidade. Se levar em conta frequência de $5 \%$ em todos forófitos amostrados, que seriam seis registros, 51 espécies amostradas no levantamento fitossociólogico $(60 \%)$ tiveram 
Tabela 3 - Espécies epifíticas vasculares amostradas no levantamento fitossociológico do Parque Estadual da Serra Furada, em ordem decrescente de valor de importância da espécie epifítica (VIe). Npi = número de forófitos ocupados pela espécie epifítica i; Nfi = número de fustes ocupados pelas espécies epifíticas i; Nci = número de copas ocupadas pelas espécies epifíticas i; FRpi = frequência relativa da espécie i nos forófitos; FRci = frequência relativa da espécie i nas copas; FRfi = frequência relativa da espécie i nos fustes.

\begin{tabular}{|c|c|c|c|c|c|c|c|}
\hline Espécie & Npi & Nfi & Nci & FRpi & FRci & FRfi & VIe \\
\hline Nidularium innocentii & 61 & 56 & 16 & 7,84 & 3,15 & 16,37 & 9,76 \\
\hline Vriesea incurvata & 60 & 35 & 42 & 7,71 & 8,27 & 10,23 & 9,25 \\
\hline Vriesea vagans & 42 & 13 & 30 & 5,40 & 5,91 & 3,80 & 4,85 \\
\hline Microgramma squamulosa & 35 & 15 & 24 & 4,50 & 4,72 & 4,39 & 4,56 \\
\hline Serpocaulon catharinae & 36 & 9 & 28 & 4,63 & 5,51 & 2,63 & 4,07 \\
\hline Peperomia catharinae & 32 & 15 & 19 & 4,11 & 3,74 & 4,39 & 4,06 \\
\hline Vriesea flammea & 30 & 10 & 23 & 3,86 & 4,53 & 2,92 & 3,73 \\
\hline Elaphoglossum glaziovii & 23 & 20 & 7 & 2,96 & 1,38 & 5,85 & 3,61 \\
\hline Vriesea platynema & 30 & 6 & 25 & 3,86 & 4,92 & 1,75 & 3,34 \\
\hline Asplenium scandicinum & 19 & 11 & 11 & 2,44 & 2,17 & 3,22 & 2,69 \\
\hline Philodendron appendiculatum & 19 & 11 & 10 & 2,44 & 1,97 & 3,22 & 2,59 \\
\hline Rhipsalis teres & 23 & 6 & 17 & 2,96 & 3,35 & 1,75 & 2,55 \\
\hline Nematanthus tessmanii & 19 & 7 & 14 & 2,44 & 2,76 & 2,05 & 2,40 \\
\hline Dichaea pendula & 17 & 7 & 12 & 2,19 & 2,36 & 2,05 & 2,20 \\
\hline Edmundoa lindenii & 20 & 4 & 16 & 2,57 & 3,15 & 1,17 & 2,16 \\
\hline Acianthera glanduligera & 17 & 5 & 13 & 2,19 & 2,56 & 1,46 & 2,01 \\
\hline Pecluma paradiseae & 14 & 6 & 11 & 1,80 & 2,17 & 1,75 & 1,96 \\
\hline Dichaea cogniauxiana & 14 & 5 & 9 & 1,80 & 1,77 & 1,46 & 1,62 \\
\hline Anthurium gaudichaudianum & 12 & 6 & 7 & 1,54 & 1,38 & 1,75 & 1,57 \\
\hline Vittaria lineata & 10 & 7 & 5 & 1,29 & 0,98 & 2,05 & 1,52 \\
\hline Wittrockia superba & 12 & 4 & 9 & 1,54 & 1,77 & 1,17 & 1,47 \\
\hline Vriesea carinata & 11 & 4 & 9 & 1,41 & 1,77 & 1,17 & 1,47 \\
\hline Rhipsalis pachyptera & 12 & 3 & 9 & 1,54 & 1,77 & 0,88 & 1,32 \\
\hline Tillandsia usneoides & 11 & 2 & 10 & 1,41 & 1,97 & 0,58 & 1,28 \\
\hline Tillandsia aeranthos & 10 & 5 & 5 & 1,29 & 0,98 & 1,46 & 1,22 \\
\hline Pleopeltis pleopeltifolia & 10 & 2 & 9 & 1,29 & 1,77 & 0,58 & 1,18 \\
\hline Campyloneurum nitidum & 8 & 3 & 7 & 1,03 & 1,38 & 0,88 & 1,13 \\
\hline Pecluma truncorum & 9 & 2 & 8 & 1,16 & 1,57 & 0,58 & 1,08 \\
\hline Peperomia tetraphylla & 9 & 2 & 8 & 1,16 & 1,57 & 0,58 & 1,08 \\
\hline Peperomia pereskiifolia & 8 & 6 & 2 & 1,03 & 0,39 & 1,75 & 1,07 \\
\hline Elaphoglossum lingua & 8 & 5 & 3 & 1,03 & 0,59 & 1,46 & 1,03 \\
\hline Pleopeltis hirsutissima & 10 & 0 & 10 & 1,29 & 1,97 & 0,00 & 0,98 \\
\hline Hymenophyllum asplenioides & 6 & 4 & 2 & 0,77 & 0,39 & 1,17 & 0,78 \\
\hline Lepismium houlletianum & 6 & 1 & 6 & 0,77 & 1,18 & 0,29 & 0,74 \\
\hline Brasiliorchis marginata. & 5 & 3 & 3 & 0,64 & 0,59 & 0,88 & 0,73 \\
\hline Codonanthe devosiana & 7 & 0 & 7 & 0,90 & 1,38 & 0,00 & 0,69 \\
\hline Rhipsalis paradoxa & 7 & 0 & 7 & 0,90 & 1,38 & 0,00 & 0,69 \\
\hline Selaginella sp. & 4 & 3 & 2 & 0,51 & 0,39 & 0,88 & 0,64 \\
\hline Tillandsia stricta & 6 & 0 & 6 & 0,77 & 1,18 & 0,00 & 0,59 \\
\hline Philodendron sp. & 4 & 4 & 0 & 0,51 & 0,00 & 1,17 & 0,58 \\
\hline Alatiglossum longipes & 5 & 1 & 4 & 0,64 & 0,79 & 0,29 & 0,54 \\
\hline Rhipsalis trigona & 5 & 0 & 5 & 0,64 & 0,98 & 0,00 & 0,49 \\
\hline Microgramma vacciniifolia & 4 & 1 & 3 & 0,51 & 0,59 & 0,29 & 0,44 \\
\hline Hymenophyllum caudiculatum & 3 & 3 & 0 & 0,39 & 0,00 & 0,88 & 0,44 \\
\hline Octomeria cf. crassifolia & 3 & 2 & 1 & 0,39 & 0,20 & 0,58 & 0,39 \\
\hline Pabstiella fusca & 2 & 1 & 2 & 0,26 & 0,39 & 0,29 & 0,34 \\
\hline Bulbophyllum sp. & 3 & 0 & 3 & 0,39 & 0,59 & 0,00 & 0,30 \\
\hline Campylocentrum aromaticum & 3 & 0 & 3 & 0,39 & 0,59 & 0,00 & 0,30 \\
\hline Sinningia douglasii & 3 & 0 & 3 & 0,39 & 0,59 & 0,00 & 0,30 \\
\hline Cyclopogon elatus & 2 & 2 & 0 & 0,26 & 0,00 & 0,58 & 0,29 \\
\hline Euterpe edulis & 2 & 2 & 0 & 0,26 & 0,00 & 0,58 & 0,29 \\
\hline Lankesterella caespitosa & 2 & 2 & 0 & 0,26 & 0,00 & 0,58 & 0,29 \\
\hline Octomeria sp. & 2 & 2 & 0 & 0,26 & 0,00 & 0,58 & 0,29 \\
\hline Acianthera sp. & 2 & 1 & 1 & 0,26 & 0,20 & 0,29 & 0,24 \\
\hline Bifrenaria sp.1 & 2 & 1 & 1 & 0,26 & 0,20 & 0,29 & 0,24 \\
\hline Campylocentrum sellowii & 2 & 1 & 1 & 0,26 & 0,20 & 0,29 & 0,24 \\
\hline Clusia criuva & 2 & 1 & 1 & 0,26 & 0,20 & 0,29 & 0,24 \\
\hline Niphidium crassifolium & 2 & 1 & 1 & 0,26 & 0,20 & 0,29 & 0,24 \\
\hline
\end{tabular}


Tabela 3 - continuação...

\begin{tabular}{|c|c|c|c|c|c|c|c|}
\hline Espécie & Npi & Nfi & Nci & FRpi & FRci & FRfi & VIe \\
\hline Tillandsia geminiflora & 2 & 1 & 1 & 0,26 & 0,20 & 0,29 & 0,24 \\
\hline Tillandsia mallemontii & 2 & 1 & 1 & 0,26 & 0,20 & 0,29 & 0,24 \\
\hline Epidendrum vesicatum & 2 & 0 & 2 & 0,26 & 0,39 & 0,00 & 0,20 \\
\hline Stelis cf. megantha & 2 & 0 & 2 & 0,26 & 0,39 & 0,00 & 0,20 \\
\hline Stelis sp. & 2 & 0 & 2 & 0,26 & 0,39 & 0,00 & 0,20 \\
\hline Anthurium sp. & 2 & 1 & 0 & 0,26 & 0,00 & 0,29 & 0,15 \\
\hline Baptistonia sp. & 1 & 1 & 0 & 0,13 & 0,00 & 0,29 & 0,15 \\
\hline Blechnum binervatum & 1 & 1 & 0 & 0,13 & 0,00 & 0,29 & 0,15 \\
\hline Campyloneuron acrocarpon & 1 & 1 & 0 & 0,13 & 0,00 & 0,29 & 0,15 \\
\hline Epidendrum cf. paniculatum & 1 & 1 & 0 & 0,13 & 0,00 & 0,29 & 0,15 \\
\hline Epidendrum cf. pseudodifforme & 1 & 1 & 0 & 0,13 & 0,00 & 0,29 & 0,15 \\
\hline Epidendrum cf. ramosum & 1 & 1 & 0 & 0,13 & 0,00 & 0,29 & 0,15 \\
\hline Huperzia mandiocana & 1 & 1 & 0 & 0,13 & 0,00 & 0,29 & 0,15 \\
\hline Lepismium cruciforme & 1 & 1 & 0 & 0,13 & 0,00 & 0,29 & 0,15 \\
\hline Mollinedia schottiana & 1 & 1 & 0 & 0,13 & 0,00 & 0,29 & 0,15 \\
\hline Philodendron sp. & 1 & 1 & 0 & 0,13 & 0,00 & 0,29 & 0,15 \\
\hline Rudgea jasminoides & 1 & 1 & 0 & 0,13 & 0,00 & 0,29 & 0,15 \\
\hline Begonia biguassuensis & 1 & 0 & 1 & 0,13 & 0,20 & 0,00 & 0,10 \\
\hline Bifrenaria cf. harrisoniae & 1 & 0 & 1 & 0,13 & 0,20 & 0,00 & 0,10 \\
\hline Billbergia nutans & 1 & 0 & 1 & 0,13 & 0,20 & 0,00 & 0,10 \\
\hline Brasiliorchis porphyrostele & 1 & 0 & 1 & 0,13 & 0,20 & 0,00 & 0,10 \\
\hline Coppensia flexuosa & 1 & 0 & 1 & 0,13 & 0,20 & 0,00 & 0,10 \\
\hline Epidendrum sp. & 1 & 0 & 1 & 0,13 & 0,20 & 0,00 & 0,10 \\
\hline Hippeastrum cf. aulicum & 1 & 0 & 1 & 0,13 & 0,20 & 0,00 & 0,10 \\
\hline Nematanthus australis & 1 & 0 & 1 & 0,13 & 0,20 & 0,00 & 0,10 \\
\hline Polystachya concreta & 1 & 0 & 1 & 0,13 & 0,20 & 0,00 & 0,10 \\
\hline \multirow[t]{2}{*}{ Promenaea riograndensis } & 1 & 0 & 1 & 0,13 & 0,20 & 0,00 & 0,10 \\
\hline & 778 & 342 & 508 & 100 & 100 & 100 & 100 \\
\hline
\end{tabular}

registro igual ou inferior à seis por forófito. Em estudo realizado por Kersten e Kuniyoshi (2009), a maioria das espécies teve frequência igual ou inferior a 5\%, considerando a maioria como raras.

Os valores obtidos por meio da análise de correlação de Spearman demonstraram que houve forte correlação positiva entre DAP e riqueza de espécies ( $r s=0,54245$; $\mathrm{p}<0,001$ ), onde árvores com diâmetros maiores apresentam maior riqueza de espécies, favorecendo o estabelecimento de espécies epifíticas por oferecerem maior área como substrato. $\mathrm{O}$ valor obtido entre altura das árvores e riqueza também foi positiva $(0,45852 ; \mathrm{p}<0,001)$, evidenciando que árvores maiores apresentam maior riqueza de espécies.

O tempo que o substrato está disponível para colonização é um fator importante para estabilização das espécies, pois forófitos de grandes dimensões (maiores alturas e diâmetros) possuem além de maior tempo, também maior diversidade de microclimas e de superfície para fixação (BENZING, 1990; BONNET; QUEIROZ, 2006; OLIVEIRA et al., 2013), e a medida que o forófito cresce, a colonização pelos epífitos vai crescendo de maneira diretamente proporcional (RIBEIRO, 2009).

Outros estudos apontam que há correlação entre riqueza e DAP, e riqueza e altura (HOELTGEBAUM, 2003; DIAS, 2009), demonstrando que a altura e o diâmetro influenciam no estabelecimento de espécies.
Flores-Palacios e Garcia-Franco (2006) relatam que existe relação positiva e linear entre o tamanho dos forófitos e a riqueza de epífitos que suportam.

Em relação a distribuição vertical dos epífitos (Tabela 3), as copas foram mais colonizadas que os fustes. Na copa foram obtidos 508 registros, enquanto que no fuste foram registrados 342 epífitos vasculares. Segundo Freiberg (1996), fatores como inclinação dos ramos e acúmulo de material orgânico, como restos de folhas, aumentam a umidade proporcionando maior colonização de bromeliaceae epifítica nessa região do forófito.

O índice de diversidade de Shannon, calculado para a comunidade epifítica do PESF foi de 3,81 e a equabilidade de Pielou de 0,85. A diversidade pode ser considerada alta quando comparada a outros estudos realizados no Sul do Brasil (Tabela 2), sendo sua diversidade apenas inferior quando comparada ao estudo de Waechter (1992). A equabilidade também foi considerada alta denotando certa uniformidade de participação de cada espécie para compor a comunidade epifítica da área.

Alguns trabalhos apresentaram resultados semelhantes aos encontrados neste estudo, considerando também o número de espécies (Tabela 2). Segundo Giongo e Waechter (2004), as áreas mais ricas estão situadas ao norte da região sul do Brasil e apresentam índices de diversidade mais elevados por possuírem influência tropical. No entanto a idade da floresta, o grau de con- 
servação e/ou de perturbação devem ser levados em consideração, aumentando ou diminuindo a diversidade da floresta. Pelo fato do PESF ter seu acesso restrito, o grau de preservação da área é maior, mantendo as espécies e justificando o índice de diversidade maior quando comparado com estudos realizados mais ao norte.

\section{Conclusão}

A riqueza específica registrada neste trabalho, no levantamento florístico e fitossociológico, evidencia a representatividade de outras formas de vida não arbóreas, ainda pouco exploradas no bioma Mata Atlântica.

A copa das árvores foi a mais colonizada pelos epífitos, justificada pelos fatores físicos dessas áreas, como inclinação de galhos e favorecimento de acúmulo de material orgânico que aumentam a umidade, podendo criar diferentes microhábitats e elevando a diversidade das espécies que habitam a copa da árvore.

A análise de correlação de Spearman aponta que há correlação positiva entre diâmetro e altura de árvores e riqueza de espécies, destacando que quanto maior a disponibilidade de substrato e o tempo de colonização, maior será a diversidade de espécies.

Estudos que visem a levantar a flora epifítica vascular são necessários para possibilitar o entendimento da comunidade florestal como um todo, considerando todas as formas de vida, pois preservar esses hábitats é condição primaz para manter a biodiversidade.

\section{Agradecimentos}

À Fundação de Amparo à Pesquisa e Inovação do Estado de Santa Catarina (FAPESC) e à CAPES pela concessão da bolsa de Mestrado do primeiro autor. Ao professor Dr. Jorge Luiz Waechter pela colaboração na confirmação e/ou identificação de algumas entidades taxonômicas.

\section{Referências}

AGUIAR, L.W.; CITADINI-ZANETTE, V.; MARTAU, L.; BACKES, A. Composição florística de epífitos vasculares numa área localizada nos municípios de Montenegro e Triunfo, Rio Grande do Sul, Brasil. Iheringia, sér. Botânica, v. 28, p. 55-93, 1981.

APG III. The Angiosperm Phylogeny Group. An update of the Angiosperm Phylogeny Group classification for the ordens and families of flowering plants: APG III. Botanical Journal of the Linnean Society, Londres, v. 161, p. 105-121, 2009.
AZEREDO, T. E. V.; CITADINI-ZANETTE, V. Aspectos florísticos, taxonômicos e ecológicos de bromélias da Mata Atlântica do sul de Santa Catarina. Revista de Estudos Ambientais, Blumenau, v. 14, n. 4, p. 20-43, 2012.

BATAGHIN, F.A.; FIORI, A.; TOPPA, R.H. Efeito de borda sobre epífitos vasculares em Floresta Ombrófila Mista, Rio Grande do Sul, Brasil. O Mundo da Saúde, v.32, p. 329-338, 2008.

BENZING, D. H. Vascular Epiphytes. New York: Cambridge University Press, 1990. 354p.

BIANCHI, J. S.; MICHELON, C.; KERSTEN, R. A. Epífitas vasculares de uma área de ecótono entre as Florestas Ombrófilas Densa e Mista, no Parque Estadual do Marumbi, PR. Estudos de Biologia: Ambiente e Diversidade, v. 34, p. 37-44, 2012.

BLUM, C. T.; RODERJAN, C. V.; GALVÃO, F. Composição florística e distribuição altitudinal de epífitas vasculares da Floresta Ombrófila Densa na Serra da Prata, Morretes, Paraná, Brasil. Biota Neotropica, Campinas, v. 11, n. 4, p. 141-159, 2011.

BONNET, A.; QUEIROZ, M. H. Estratificação vertical de bromélias epifíticas em diferentes estádios sucessionais da Floresta Ombrófila Densa, Ilha de Santa Catarina, Santa Catarina, Brasil. Revista Brasileira de Botânica, São Paulo, v. 29, n. 2, p. 217-228, 2006.

BONNET, A.; QUEIROZ, M. H.; LAVORANTI, O. J. Relações de bromélias epifíticas com características dos forófitos em diferentes estádios sucessionais da Floresta Ombrófila Densa. Floresta, Curitiba, v. 37, p. 83-94, 2007.

BORGO, M.; SILVA, S.M.; PETEAN, M. Epífitos vasculares em um remanescente de floresta estacional semidecidual, município de Fênix, PR, Brasil. Acta Biologica Leopoldensia, n. 24, p. 121-130, 2002.

BORGO, M.; SILVA, S.M. 2003. Epífitos vasculares em fragmentos de Floresta Ombrófila Mista, Curitiba, Paraná, Brasil. Revista Brasileira de Botânica, São Paulo, n. 26, p. 391-401, 2003.

BREIER, T. B. O epifitismo vascular nas Florestas do Sudoeste do Brasil, São Paulo, SP. 2005. 139 f. Tese (Doutorado em Biologia Vegetal) - Universidade Estadual de Campinas, Campinas, 2005.

BUZATTO, C. R. et al. Composição florística e distribuição ecológica de epífitos vasculares na Floresta Nacional de Passo Fundo, Rio Grande do Sul. Iheringia, sér. Botânica, Porto Alegre, v. 63, n. 2, p. 231-239, 2008. 
CAGLIONI, E. et al. Epífitos vasculares predominantes em zonas ecológicas de forófitos, Santa Catarina, Brasil. Revista de Estudos Ambientais, Blumenau, v. 14, n. 1, p. 28-42, 2012.

CALLEGARI-JACQUES, S. M. Bioestatística: princípios e aplicações. 1. ed. Porto Alegre: Artmed, 2003. 256 p.

CERVI, A.C.; BORGO, M. Epífitos vasculares no Parque Nacional do Iguaçu, Paraná-Levantamento preliminar. Fontqueria, v. 55, p. 415-422, 2007.

COELHO, M. A. N. Flora Fanerogâmica do Reserva Biológica do Parque Estadual das Fontes do Ipiranga (São Paulo, Brasil). Família Araceae. Hoehnea, São Paulo, v. 27, p. 33-39, 2000.

COTTAM, G.; CURTIS, J. T. The use of distance measurements in phytosociological sampling. Ecology, Ithaca, v. 37, n. 37, p. 451-460, 1956.

DETTKE, G. A.; ORFRINI, A. C.; MILANEZE-GUTIERRE, M. A. Composição florística e distribuição de epífitas vasculares em um remanescente alterado de Floresta Estacional Semidecidual no Paraná, Brasil. Rodriguésia, Rio de Janeiro, v. 59, n. 4, p. 859-872, 2008.

DIAS, A. S. Ecologia de epífitas vasculares em uma área de Mata Atlântica do Parque Nacional da Serra dos Órgãos, Teresópolis, RJ. 2009. 81 f. Dissertação (Mestrado em Ciências Ambientais e Florestais) Universidade Federal Rural do Rio de Janeiro, Seropédica, 2009.

DISLICH, R.; MANTOVANI, W. Flora de epífitas vasculares da Reserva da Cidade Universitária "Armando de Salles Oliveira" (São Paulo, Brasil). Boletim de Botânica da Universidade de São Paulo, São Paulo, v. 17, p. 61-83, 1998.

DITTRICH, V. A. O.; KOZERA, C.; SILVA, S. M. Levantamento florístico dos epífitos vasculares do Parque Barigüi, Curitiba, Paraná, Brasil. Iheringia, Porto Alegre, n. 52, p. 11-21, 1999.

EPAGRI. Empresa de Pesquisa Agropecuária e de Extensão Rural de Santa Catarina. Dados e informações bibliográficas da unidade de planejamento regional litoral sul catarinense-UPR8. Florianópolis: EPAGRI, 2001. 1 CD ROM.

FATMA. Fundação do Meio Ambiente. Plano de Manejo do Parque Estadual da Serra Furada: Diagnóstico e Planejamento. Florianópolis: FATMA, 2009.

FILGUEIRAS, T. S. et al. Caminhamento: um método expedito para levantamentos florísticos qualitativos.
Cadernos de Geociências, Rio de Janeiro, n. 12, p. 39-43, 1994.

FISCHER, E. A.; ARAÚJO, A. C. Spatial organization of a bromeliad community in the Atlantic Rainforest, southeastern Brazil. Journal of Tropical Ecology, Cambridge, v. 11, p. 550-567, 1995.

FLORES-PALACIOS, A.; GARCÍA-FRANCO J. G. The relationship between tree size and epiphyte species richness: testing four different hypotheses. Journal of Biogeography, Malden, v. 33, p. 323-330, 2006.

FREIBERG, M. Spatial distribution of vascular epiphytes on three emergent Canoyi trees in French Guiana. Biotropica, Malden, v. 28, n. 3, p.345-355, 1996.

GENTRY, A. H.; DODSON, C. H. Diversity and biogeography of neotropical vascular epiphytes. Annals of the Missouri Botanical Garden, Saint Louis, v. 74, p. 205-233, 1987.

GIONGO, C.; WAECHTER, J. L. Composição florística e estrutura comunitária de epífitos vasculares em uma floresta de galeria na Depressão Central do Rio Grande do Sul. Revista Brasileira de Botânica, São Paulo, v. 27, n. 3, p. 563-572, 2004.

GONÇALVES, C. N.; WAECHTER, J. L. Aspectos florísticos e ecológicos de epífitos vasculares sobre figueiras isoladas no norte da planície costeira, RS. Acta Botanica Brasilica, Brasília, v. 17, n. 1, p. 1-17, 2002.

GUIMARÃES, E. F. Flora Fanerogâmica do Reserva Biológica do Parque Estadual das Fontes do Ipiranga (São Paulo, Brasil). Família Piperaceae. Hoehnea, São Paulo, v. 15, p. 46-51, 1998.

HAMMER, O; HARPER, D. A. T.; RYAN, P. D. PAST: Paleontological statistics, versão 1.89, 2009. Disponível em: <http://folk.uio.no/ohammer/past>. Acesso em: 16 maio 2014.

HEFLER, S. M.; FAUSTIONI, P. Levantamento florístico de epífitos vasculares do Bosque São Cristóvão, Curitiba, Paraná, Brasil. Revista Estudos de Biologia, Curitiba, v. 26, n. 54, p. 11-19, 2004.

HERTEL, R.J.G. 1949. Contribuição à ecologia de flora epífita da Serra do Mar (vertente oeste) do Paraná. Tese de concurso à livre docência, Faculdade de Filosofia, Ciências e Letras da Universidade do Paraná, Paraná, 1949.

HOEHNE, F. C. Orchidáceas. In: HOEHNE, F. C. (Ed.). Flora Brasilica. São Paulo: Instituto de Botânica, v. 12, p. 1-218, 1942. 
HOEHNE, F. C. Orchidáceas. In: HOEHNE, F. C. (Ed.). Flora Brasilica. São Paulo: Instituto de Botânica, v. 12, p. 1-389, 1945.

HOEHNE, F. C. Iconografia das Orchidaceas do Brasil. São Paulo: Secretaria da Agricultura, Indústria e Comércio, 1949. 302 p.

HOEHNE, F. C. Orchidáceas. In: HOEHNE, F. C. (Ed.). Flora Brasilica. São Paulo: Instituto de Botânica, v.12, p. 1-397, 1953.

HOELTGEBAUM, M. P. Composição florística e distribuição espacial de bromélias epifíticas em diferentes estádios sucessionais da Floresta Ombrófila Densa, Parque Botânico do Morro Baú, Ilhota/SC. 2003. 138 f. Dissertação (Mestrado em Biologia Vegetal) - Universidade Federal de Santa Catarina, Florianópolis, 2003.

INGRAM, S. W.; NADKARNI, N. M. Composition and distribution of epiphytic organic matter in a neotropical cloud forest, Costa Rica. Biotropica, Malden, v. 25, p. 370-383, 1993.

JOHANSSON, D. R. Ecology of vascular epiphytes in West African rain forest. Acta Phytogeographica Suecica, Cincinnati, v. 59, p. 1-136, 1974.

KERSTEN, R. A.; SILVA, S. M. Composição florística e estrutura do componente epifítico vascular em floresta da planície litorânea na Ilha do Mel, Paraná, Brasil. Revista Brasileira de Botânica, São Paulo, v. 24, p. 213-226, 2001.

KERSTEN, R.A.; SILVA, S.M. Florística e estrutura do componente epifítico vascular em floresta ombrófila mista aluvial do rio Barigüi, Paraná, Brasil. Revista Brasileira de Botânica, v. 25, n.3, p 259-267, 2002.

KERSTEN, R.A; SILVA, S.M. The floristic compositions of vascular epiphytes of a seasonally inundated forest on the coastal plain of Ilha do Mel Island, Brazil. Revista de Biologia Tropical, v.54, n. 3, p.935-942, 2006.

KERSTEN, R. A. Epifitismo vascular na bacia do Alto Iguaçu, Paraná. 2006. 231 f. Tese (Doutorado em Engenharia Florestal) - Universidade Federal do Paraná, Curitiba, 2006.

KERSTEN, R. A.; KUNIOSHI, Y. S. Conservação das florestas na Bacia do alto Iguaçu, Paraná - avaliação da comunidade de epífitas vasculares em diferentes estágios serais. Floresta, Curitiba, v. 39, n. 1, p. 5166, 2009.

KERSTEN, R.A., KUNIYOSHI, Y.S.; RODERJAN, C.V.
Epífitas vasculares em duas formações ribeirinhas adjacentes na bacia do rio Iguaçu, Terceiro Planalto Paranaense. Iheringia, sér. Bot. v. 64, n. 1, p. 33-43, 2009.

KERSTEN, R. A.; Epífitas vasculares - Histórico, participação taxonômica e aspectos relevantes, com ênfase na Mata Atlântica. Hoehnea, São Paulo, v. 31 , n.1, p. 9-38, 2010.

KRESS, W. J. The systematic distribution of vascular epiphytes: an update. Selbyana, Sanatosa, v 9, p. 2-22, 1986.

MACEDO, T. S.; NONATO, F. R. Levantamento das Pteridófitas ornamentais na cidade de Salvador, Bahia. Sitientibus, Feira de Santana, v. 9, n. 4, p. 255-262, 2009.

MADISON, M. Vascular epiphytes: The systematic occurrence and salient features. Selbyana, Sanatosa, v. 2, p. 1-13, 1977.

MAGURRAN, A. E. Ecological diversity and its measurement. Princeton: Princeton University, 1988. $192 \mathrm{p}$.

MARTINELLI, G. et al. Bromeliaceae da Mata Atlantica: lista de especies, distribuição e conservação. Rodriguésia, Rio de Janeiro, v. 59, p. 209-258, 2008.

MENEZES L. C. Laelia purpurata. Rio de Janeiro: Expressão e Cultura, 1985. 143 p.

MENEZES, L. C. Cattleya labiata Lindley. Orquídeas Brasileiras. Rio de Janeiro: Expressão e Cultura, 1987. $112 \mathrm{p}$.

MORAES, C. P.; SANTOS, N. S.; MASSARO, R.; CORDEIRO, G. M. Desenvolvimento In Vitro de Cattleya tigrina A. Richard (Orchidaceae) utilizando fertilizantes comerciais. Ensaios e Ciência, v. 13, n. 2, 2009.

MORAN, R. C. Polypodiaceae. In: DAVIDSE, G.; SOUSA. M.; KNAPP. S. (Ed.). Flora Mesoamericana. v. 1, Psilotaceae a Salviniaceae. México: Universidad Nacional Autónoma de México, 1995. p. 359-363.

MUELLER-DOMBOIS, D; ELLENBERG, H. Aims and methods of vegetation ecology. 2. ed. New Jersey: The Blackburn press, 2002. 547 p.

NEGRELLE, R. R. B.; MURARO, D. Aspectos fenológicos e reproditivos de Vriesia incurvata Gaudich (Bromeliaceae). Acta Scientiarum Biological Science, Maringá, v. 28, n. 2, p. 95-102, 2006. 
NIEDER, J. et al. Biodiversidad de epífitas: una cuestión de escala. Revista del Jardim Botânico Nacional, La Habana, v. 18, p. 12-13, 1996.

NIEDER, J.; ENGWALD, S.; KLAWUN, M.; BARTHLOTT, W. Spatial distribution of vascular epiphytes (including hemiepiphytes) in a lowland amazonian rain forest (Surumoni Crane Plot) of southern Venezuela. Biotropica, Malden, v. 32, p. 385-396, 2000.

OLIVEIRA, L. C.; PADILHA, P. T.; DALMOLIN, E. B.; AZEREDO, T. E. V.; CITADINI-ZANETTE, V. Componente epifítico vascular de um Fragmento Florestal Urbano, município de Criciúma, Santa Catarina, Brasil. Biotemas, Florianópolis, v. 26, n. 2, p. 33-44, 2013.

PABST, G. F. J.; DUNGS, F. Orchidaceae Brasilienses. Hildesheim: Brucke-Verlag Kurt Schmersow, v. 1, 1975. 408p.

PABST, G. F. J.; DUNGS, F. Orchidaceae Brasilienses. Hildesheim: Brucke-Verlag Kurt Schmersow, v. 2, 1977. $418 \mathrm{p}$.

PERLEBERG, T. D.; GARCIA, E. N.; PITREZ, S. R. Epífitos vasculares em área com floresta estacional semidecidual, Pelotas, Rio Grande do Sul, Brasil. Ciência e Natura, Santa Maria, v. 35, n. 2, p. 65-73, 2013.

PETEAN, M.P. 2002. Florística e estrutura dos epífitos vasculares em uma área de Floresta Ombrófila Densa Altomontana no Parque Estadual do Pico do Marumbi, Morretes, Paraná, Brasil. Dissertação de mestrado, Universidade Federal do Paraná, Paraná, 2002.

PETEAN, M. P. O componente epifítico vascular em Floresta Ombrófila Densa no litoral paranaense: análise florística, estrutural e de biomassa. 2009. 75 f. Tese (Doutorado em Conservação da Natureza) Universidade Federal do Paraná, Curitiba, 2009.

PIELOU, E. C. Ecological diversity. New York: Wiley, 1975. $165 \mathrm{p}$.

REITZ, R. Bromeliáceas e a malária: bromélia endêmica. In: Flora Ilustrada Catarinense. Iatajaí: HBR, 1983. 518 p.

RIBEIRO, D. C. A. Estrutura e composição de epífitas vasculares em duas formações vegetais na Ilha da Marambaia , Mangaratiba, RJ. 2009.99 f. Dissertação (Mestrado em Ciências Ambientais) - Universidade Federal Rural do Rio de Janeiro, Rio de Janeiro, 2009.
ROGALSKI, J.M.; ZANIN E.M. Composição florística de epífitos vasculares no estreito de Augusto César, Floresta Estacional Decidual do Rio Uruguai, RS, Brasil. Revista Brasileira de Botânica, v. 26, p.551-556, 2003.

SANTOS, C. G. M. Distribuição espacial, fenologia e polinização de Bromeliaceae na Mata Atlântica do Alto da Serra de Paranapiacaba, SP. 2000. 112 f. Tese (Doutorado em Biologia Vegetal) - Universidade Estadual de Campinas, Campinas, 2000.

SANTOS, A. C. L. Composição florística e estrutura da comunidade de epífitas vasculares associadas a trilhas no Parque Estadual das Fontes do Ipiranga, São Paulo, SP, Brasil. 2008. 72 f. Dissertação (Mestrado em Biodiversidade Vegetal e Meio Ambiente) - Instituto de Botânica da Secretaria do Meio Ambiente, São Paulo, 2008.

SAZIMA, I.; VOGEL, S.; SAZIMA, M. Bat Pollination of Encholirium glaziovii, a terrestrial bromeliad. Plant Systematics and Evolution, Jena, v. 168, p. 167-179, 1989.

SCHÜTZ-GATTI, A. L. S. 2000. O componente epifítico vascular na reserva natural Salto Morato, Guaraqueçaba - PR. Dissertação de Mestrado em Botânica. Universidade Federal do Paraná, PR, 2000.

SMITH, A. R. et al. A classification for extant ferns. Taxon, Bratislava, v. 55, n. 3, 2006.

STAUDT, M. G.; LIPPERT, A. P. U.; CUNHA, S.; BECKER, D. F. P; MARCHIORETTO, M. S.; SCHMITT, J. L. Composição florística de epífitos vasculares do Parque Natural Municipal Tupancy, Arroio do Sal, RS, Brasil. Pesquisas, Botânica, Porto Alegre, n. 63, p.177-188, 2012.

STEEGE, H. TER.; CORNELISSEN, J. H. C. Distribution and ecology of vascular epiphytes in lowland rain forest of Guyana. Biotropica, Malden, v. 21, n. 4, p. 331-339, 1989.

TAMASHIRO, J.Y; ZICKEL, C. S. Flora Fanerogâmica do Reserva Biológica do Parque Estadual das Fontes do Ipiranga (São Paulo, Brasil). Família Cactaceae. Hoehnea, Campinas, v. 18, p. 137-141, 1991.

TRYON, R. M. Development and evolution of ferns floras on oceanic islands. Biotropica, Malden, v. 2, p. 76-84, 1970.

WAECHTER, J. L. Epífitos vasculares da mata paludosa do Faxinal, Torres, Rio Grande do Sul, Brasil. Iheringia, Porto Alegre, v. 34, p. 39-49, 1986. 
WAECHTER, J. L. O epifitismo vascular na Planície Costeira do Rio Grande do Sul. 1992. 163 f. Tese (Doutorado em Ecologia e Recursos Naturais) Universidade Federal de São Carlos (UFSCar), São Carlos, 1992.

WAECHTER, J. L. Epifitismo em uma floresta de restinga do Brasil subtropical. Ciência e Natura, Santa Maria, v. 20, p. 43-66, 1998.

WAECHTER, J. L. Diversidade epifítica ao longo de gradientes ambientais. In: MARIATH, J. E. A; SANTOS, R. P. (Org.). Os avanços da botânica no início do século XXI: morfologia, fisiologia, taxonomia, ecologia e genética. Porto Alegre: Sociedade Botânica do Brasil, 2006.

WAECHTER, J. L. Diversidade de epífitos vasculares na Floresta Atlântica brasileira. In: LOIOLA, M. I. B.; BASEIA, I. G.; LICHSTON, J. E. (Org.). Atualidades, desafios e perspectivas da Botânica no Brasil. Natal: Sociedade Botânica do Brasil, 2008. p. 310-312.

WANDERLEY, M. G. L.; MARTINS, S. E. Bromeliaceae. In: WANDERLEY, M. G. L.; SHEPHERD, G. J.; MELHEM, T. S.; GIULIETTI, A. M. (Coord.). Flora fanerogâmica do Estado de São Paulo. São Paulo: Instituto de Botânica, 2007. p. 39-61.

ZAR, J. H. Biostatistical analysis. 4. ed. New Jersey: Prentice Hall, 1999. 459 p.

ZOTZ, G.; HIETZ, P. The physiological ecology of vascular epiphytes: current knowledge, open questions. Journal of Experimental Botany, Oxford, v. 52, n. 364, p. 2067-2078, 2001.

ZOTZ, G. The systematic distribution of vascular epiphytes - a critical update. Botanical Journal of the Linnean Society, Londres, v. 171, n. 3, p. 453481, 2013. 